\title{
The Importance of Predictive Human Competence in the Stress Resistance
}

\author{
Alina Bunas, Yana Amineva \& Irina Arshava \\ Department of General and Medical Psychology \\ Oles Honchar Dnipropetrovsk National University \\ Dnipropetrovsk, Ukraine
}

\begin{abstract}
The conceptualization of predictive human potential as a constructive anticipatory coping in the life stressful situation is offered. The objective of this study was to examine the role of predictive human potential as the ability of personality to cope with difficult life situations (or to resist stress) and as a vital component of establishing psychological well-being. Predictive potential allows a person to foresee possible upsetting or sorrowful events and be ready to face them increasing stress resistance and leading to decrease of psychological traumas. Predictive human competence as a diverse psychological phenomenon realized in anticipatory coping with a real-life stressful situation should be analyzed via the level of development of personality characteristics (ambiguity tolerance, hardiness and risk propensity) that form their individual predictive potential. The research results suggest that predictive competence is fundamental in understanding coping ability and make a contribution to the body of research on the relationship between personality and uncertainty.
\end{abstract}

Keywords: real-life stressful situation, predictive human potential, predictive competence, ambiguity, hardiness, risky behavior, tolerance to uncertainty, stress resistance.

\section{INTRODUCTION}

A rapidly changing world nowadays creates instability, uncertainty and ambiguity of people's lives. One of the topical tendencies of psychological science in researching ambiguity is the analysis of a real-life stressful situation.

The term a real-life stressful situation is commonly encountered in different spheres of science. Within a conceptual scheme of psychological science the term reveals a methodological mismatch since in some scientific works it is understood as a general category, in the others, however, it is used in a much narrower, more specific sense labelling types of life events, such as disease, problems in social interaction or visions of the future and the like [39;2].

The term a real-life stressful situation is commonly encountered in different spheres of science. Within a conceptual scheme of psychological science the term reveals a methodological mismatch since in some scientific works it is understood as a general category, in the others, however, it is used in a much narrower, more specific sense labelling types of life events, such as disease, problems in social interaction or visions of the future and the like.

A real-life situation analysed from psychological point of view could be found stressful according to some important characteristics. The characteristics are widely mentioned in scientific literature: depth, running time, importance, uncontrollability, ambiguity, stressfulness, risk, inadaptability (high demands to stress adaptation) etc. [12; 44]. Researcher K. Vasylevska proposes an empirical criterion for a real-life stressful situation impoverishment of the past, the loss of childhood and ontologization of the present [21]. The first phenomenon deals with presenting much smaller number of life events in stressful 
situations compared to un-stressful, habitual situations. In difficult times people enumerate the most important life events, the main stages of their personal history: birth, studying, marrige etc. The examined people, who experienced difficulties at the time of the research, presented their lives since "the age of reason, "approximately 15 years old, which reveals the phenomenon called the loss of childhood. At the same time the respondents remembered the events from their childhood but not as essential or significant for the present situation. The criterion of ontologization of the present covers the spread of the present time over the whole period under stress. It is characterized by constant rethinking the situation with the feeling of its full uncontrollability [27]. Thus, during stressful life events personality possesses limited vital resources (a limited capacity to contruct 'subject-future' relations) and appears unable to show a variety of behavior repertoire towards future events. In this case a question of integrative qualities of personality seems interesting to research. In the process of coping with a real-life stressful situation personality develops a psychological ability (so-called predictive human potential), which creates an important aspect of their life span.

The objective of the article is to show the role of predictive human potential as the ability of personality to cope with difficult life situations (or to resist stress) and as a vital component of establishing psychological well-being. Predictive potential allows a person to foresee possible upsetting or sorrowful events and be ready to face them increasing stress resistance and leading to decrease of psychological traumas.

\section{EXISTING RESEARCH FINDINGS}

Psychological analysis gives the opportunity to sort out the nuclear component of predictive potential - predictive human competence. The term predictive competence is understood as a human capacity to foresee the coming events with a high degree of probability, predict the development of events and personal reactions to them, act in advance [32]. Thus, the concept characterizes an appropriate development of anticipated skills of personality, the system of their inner recourses which guarantee success in prognostic activity [34]. All in all, predictive competence is a characteristic of personality but it starts functioning as a mental human process revealed in stressful situations as a specific form of prediction.

Manifestation of prediction competence depends on the aims and objectives of person's activity, its time span, spatial or person-situation characteristics. For instance, person-situation competence is a type of prognostication which is connected with the ability to foresee variety of events and be prepared for them (monovariant or poly variant prognostication). In case of monovariant prognostication an individual predicts only one trend of events. If prognostication is poly variant, there are predictions for a variety of trends so an individual is expected to be more prepared for any unusual situation. Spatial competence ensures kinaesthetic setup (variations of body movements in an appropriate direction), orientation in space [15]. Time prognostication demonstrates the ability to manage time and plan appropriately (chronorhythmoability or chronorhythmodisability). It should be noted that all the forms of prognostication mentioned above are aimed at future, at people's capacity to act according to a predictive scheme towards stressful life events, mentally foresee future actions constructing forecasts, hypothesis, plans and so on [45].

Predictive competence is a stable characteristic of human psyche when mapping the environment. According to a range of scientific research $[31 ; 43 ; 11 ; 19 ; 14 ; 13 ; 38]$ the above mentioned competence is relatively independent, autonomous characteristic of personality among other traits. Its interconnection with other characteristics of human psyche is nonlinear, multivariate, indirect, so we can consider it to be psychologically heterogeneous phenomenon that has an impact on human adaptation and behavior regulation. It is unquestionable that the ability of a person to predict the results and consequences of their 
behavior determines the decisions a person will make: what and how the person will act under stress. It means that one of the most important stages of studying the diversity of individual behavior and acting in stressful situations is the analysis of a peculiar predictive competence of a particular personality, their ability to prognosticate and predict the results of their actions, pattern their behavior and design a new behavioural programme [40].

Taxing circumstances, which might create personal feelings of fear, uncertainty and insecurity, and lead a person to the lack of confidence in successful managing of their life, must be taken into account in stress resistance potential of an individual, who shows new behavioural patterns aimed at coping with the situation. B. Anan'ev points out that person-situation interaction forms a wide range of social situations with potential for self-development. Under the given circumstances an individual performs a variety of social functions that demonstrate a range of personal qualities [3]. Undoubtedly, the main goal of any stressful life period is promotion to positive changes in personality as L. Vygotsky claimed [33]. In this regard a reallife stressful situation should also be treated as aggravation of developmental contradictions, "a compulsory turning point, critical moment after which development will follow this or that route using the possibilities for personal growth" [37; 39]. As a result, besides a destructive influence on a person a real-life stressful situation has a constructive potential as well (selfdevelopmental value due to the development of predictive competence).

Adaptation to new life circumstances that are subjectively perceived as stressful is ensured by its predictive potential that includes integrative qualities of a person such as tolerance of uncertainty, hardiness and propensity to risk as a tendency to reveal new behavioural reactions.

According to the theory of homeostasis, it is quite natural that most people who experience uncertainty and ambiguity of situation feel insecure, anxious or frustrated facing something unknown and unforeseeable, and try to avoid unpredictable situations. But apart from a destructive influence ambiguity can stimulate other responses such as seeking to minimize or reduce stress or conflict, promoting the increase of such psychological virtue as tolerance of uncertainty. B. Anan'ev emphasized the importance of studying ambiguity and pointed out that "ambiguity among different forms of tension is a finding of paramount importance", "it is a characteristic of dynamic psyche nowadays that sets new scientific problems" [3]. S. Budner defines tolerance as "individual tendency to perceive (or evaluate) uncertain, ambiguous situations as favourable or (in case of ambiguity intolerance) as threatening" [37]. In present studies ambiguity tolerance is regarded as an independent psychological construct that influences perception, thinking, emotional and behavioural spheres, as the relationship that individuals have with ambiguous and uncertain stimuli or events interpreting them not as threatening but challenging (motivating to behave in a risky manner) [36], or as an ability to bear tension in critical, problematic situations [27].

Based on the above-mentioned statements, ambiguity tolerance could be viewed as a subjective factor that provides hardiness in critical situations that are created by specific conditions of human life.

Hardiness is one more psychological phenomenon first presented as a personality style by S. Maddi He conceives of hardiness as a pattern of certain attitudes and motivation needed to modify the environment into opportunities of a personality [28]. According to D.Leont'eV and 0 . Rasskazova hardiness is a system of human beliefs and values about themselves and the word around, personality relationship with the surrounding world. It indicates a human adaptability and a resistance resource in the encounter with stressful conditions measuring person's ability to turn stressful circumstances from potential calamities into opportunities for personal growth $[25 ; 7 ; 29]$. 
The concept of hardiness is viewed as a combination of three dispositions - commitment, control, and challenge. Similar to hardiness there are such psychological categories as personal adaptive potential (A. Maklakov), subjectivity (B. Anan'ev K. Abulrhanova-Slavsra and others), existential personal potential (D. Leont'ev). Hardiness is not a strategy in coping with a real-life stressful situation, it is a source of human potentials which encourage personality development and self-improvement. Hardiness is closely connected with individual's choice of behavior in a stressful situation: either to follow their previous experience and change nothing or to put stressful circumstances into perspective and interpret them in a less threatening manner endeavouring to find new ways and approaches in solving problems, taking risks, developing their personality [2].

According to dynamic paradigm of psychology of choice, which ranks the variants of decisionmaking, propensity to risk is seen as a certain trend that dictates a particular behavior repertoire, and may lead to unpredictable (positive and/or negative) results. Taking risks in life is a common occurrence amongst all human beings, it is an inseparable part of human life nowadays, part of functioning of modern society $[4 ; 13]$.

Risky behavior is a means of increasing self-adaptability in the inner and outer setting which impacts keeping person's individuality (individualization of personality is a process of psychological development and self-realization when unique personality features are fulfilled) [19].

D. Kolesov considers risk to be connected with threat and danger. Danger is a troublesome and hostile force that contradicts human intentions. Threat is a realization of danger. Awareness of threat in the situation of danger transforms any life situation into a risky situation, and risk is a form of resistance to threat and danger [35]. In researching risky behavior as a certain strategy of coping with stressful situations V. Cherkasova takes into consideration subjective concept, focused on the doer or the subject of the action, as a possible choice of behavior and its outcomes. From the point of view of the concept, taking risks, which comes with human intelligence and will, leads and drives people's behavior in making decisions about whether or not to take such risks [16;33].

On the one hand propensity to risk has an objective, fact-based nature, on the other it is subjective and personal as an individual is always responsible for their decision-making and choice of their behavior. We believe risk propensity to be the component of predictive human potential because of individual's responsibility for their own choice of predicted course of events. Understanding of situation, personal attitude, certain aims and skills etc. are involved in the process of decision-making. In other words, in the situation of ambiguity and uncertainty an individual demonstrates risk propensity as one of the forms of prognostication and prediction of their own choice.

In conclusion, predictive human competence as a diverse psychological phenomenon realized in coping with a real-life stressful situation should be analysed via the level of development of personality characteristics (ambiguity tolerance, hardiness and risk propensity) that form their individual predictive potential.

\section{METHOD}

\section{Participants}

Our empirical research of predictive human potential in stress resistance was two-staged. On the first stage we studied those psychological traits of personality which obviously are the sources of predictive human competence in a stressful situation. They are hardiness and ambiguity tolerance. The respondents chosen were the people who experienced hard times in 
their lives during the research (imprisonment, serious disease, unemployment etc.) and perceived the situation as stressful. There were 222 participants aged 18 to 60 on the first stage of the research.

The second stage was aimed at researching the role of risk propensity in developing predictive human potential. The sample consisted of 215 adults (108 male and 107 female) aged from 18 to 35 years.

\section{Data tools}

Hardiness Survey by S. Maddi reveals an individual's ability to remain healthy under life stress, to maintain inner balance and high productivity. Russian version of the survey adapted by D. Leont'ev and O. Rasskazova (2006) was used in the empirical research under consideration. The version includes three comparatively autonomous components - involvement, control and acceptance of risk. It also makes possible to assess the general level of hardiness.

Intolerance of Ambiguity Scale by Budner was used in translation and adaptation by G. Soldatova and L. Shaigerova (2008). The level of personal tolerance-intolerance to uncertainty can be assessed by the Scale by means of three subscales - novelty of the problem, its complexity and solution potential. It must be noted that the higher the participant's rank according to the Scale, the lower level of tolerance the person demonstrates towards ambiguity of the situation.

Anticipation ability by V. Mendelevich (1996) shows the development of three scales - personsituation, spatial and time prognostication competence, and gives the general level of predictive human competence. Possessing the ability, an individual functions more effectively in decision-making process, stating the aims, choosing their behavior repertoire, planning and controlling.

Predictive ability by L. Regush (2003) is a total number of points given between the options a or $\mathrm{b}$ with 1 or 2 points respectively. According to our hypothesis we focused on the general predictive ability, which was seen as "the basis" for the development of predictive human competence.

Propensity to risk by A. Shmel'ov aims at defining of risky behavior level and discovery of overwhelming characteristic tendencies. Risk propensity index makes from 11 to 40 points. The analysis of risk propensity, which is seen as a trait of character, is important for psychological prediction in making decisions under the conditions of uncertainty or ambiguity.

\section{Procedure}

With the help of the method of cluster analysis (K-means algorithm) the sample of participants was split into two or three groups on the variables of hardiness, ambiguity tolerance and predictive competence. The examined were divided into clusters (according to the rate of average data point of all the variables). After that the between cluster differences were computed and the differences were assessed by t-test. Most differences proved to be statistically important at $\mathrm{p} \leq .001$.

\section{RESULTS AND DISCUSSION}

The hypothesis of the research first stage was the statement that if an individual shows a high level of hardiness to resist a stressful life situation, then the level of ambiguity intolerance will be low, which guarantees the functioning of predictive human competence.

The first cluster demonstrates the highest indices of different components of hardiness and the general level of it. The third cluster is formed of low indices according to the above mentioned variables in the sample. Differences between the variables, used for clusterization, were 
processed with the help of t-test (see Tables 1, 2, 3, 4).

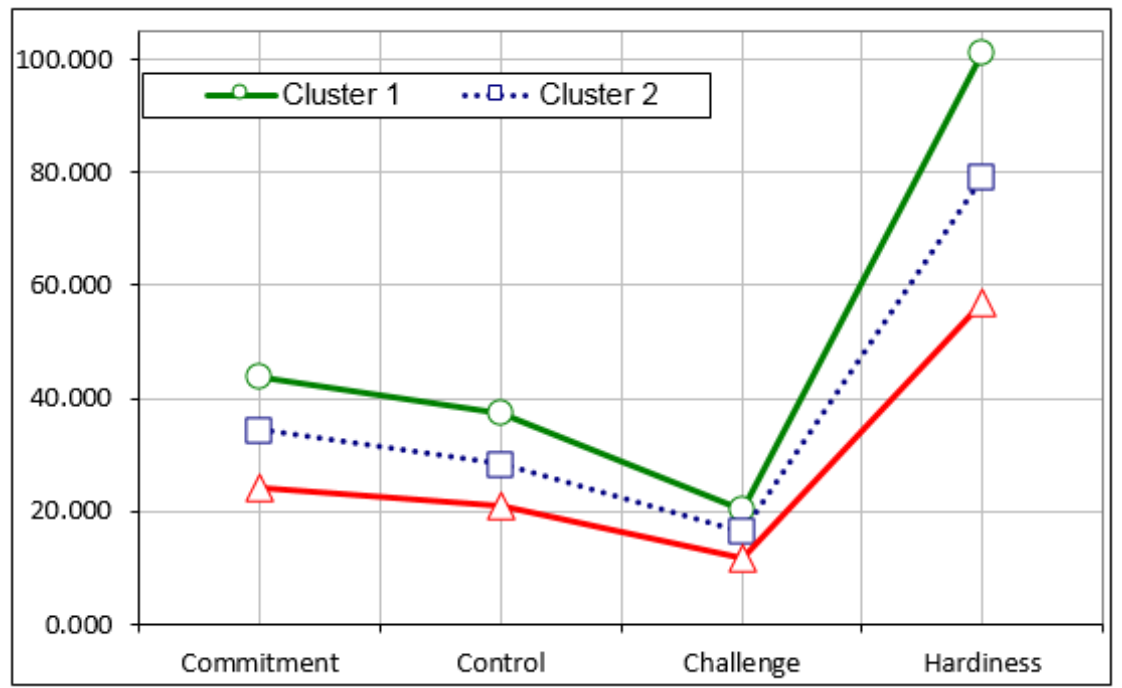

Figure 1: The results of clusterization of the sample

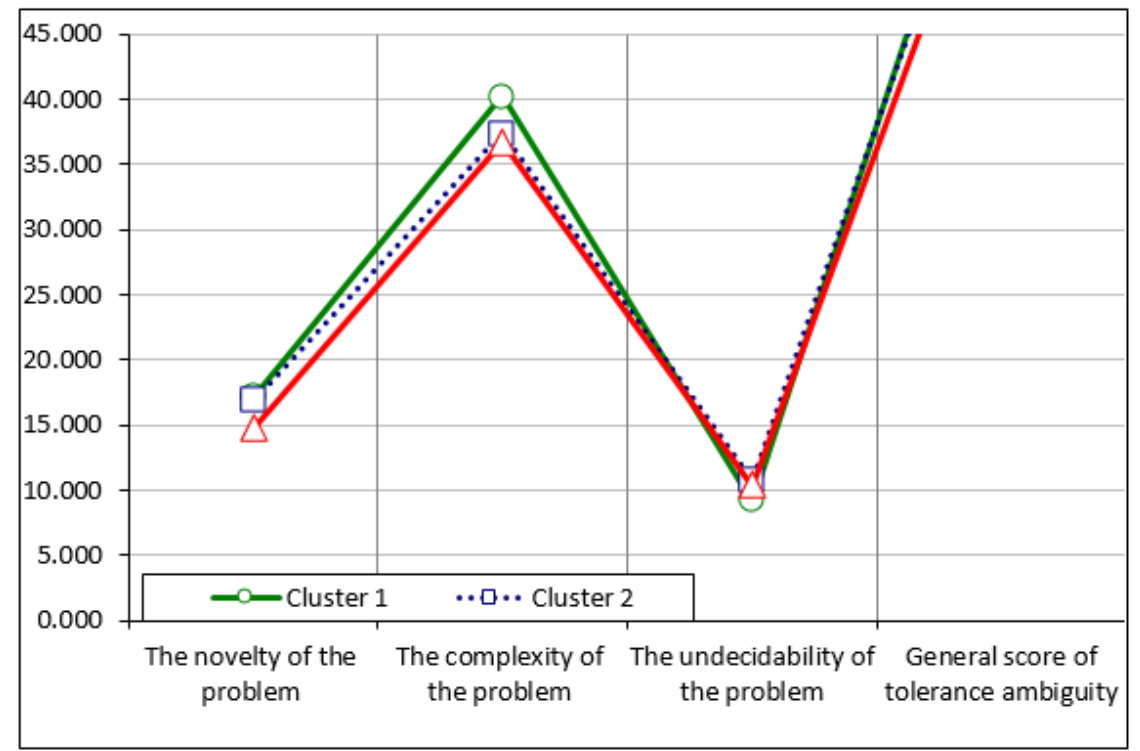

Figure 2: The results of clusterization of the sample

The clusterization showed some differences in the indices of the variables analyzed. According to the results from Table 1, opposite clusters 1 and 3 differ in all the indices.

Table 1: Between cluster differences in hardiness and tolerance ambiguity

\begin{tabular}{|c|c|c|c|}
\hline Variables & $\begin{array}{l}\text { Mean } \\
\text { Cluster } 1 \\
(N=59)\end{array}$ & $\begin{array}{l}\text { Mean } \\
\text { Cluster } 3 \\
(N=52)\end{array}$ & t-value \\
\hline Commitment & 43,610 & 24,173 & $23,967^{*}$ \\
\hline Control & 37,305 & 21,096 & $18,735^{*}$ \\
\hline Challenge & 20,237 & 11,692 & $10,027^{*}$ \\
\hline Hardiness & 101,153 & 57,000 & $29,176^{*}$ \\
\hline The novelty of the problem & 17,254 & 14,788 & $2,822^{*}$ \\
\hline The complexity of the problem & 40,220 & 36,731 & $2,808^{*}$ \\
\hline The undecidability of the problem & 9,136 & 10,308 & $-1,938^{*}$ \\
\hline General score of tolerance ambiguity & 66,627 & 61,827 & $2,955^{*}$ \\
\hline
\end{tabular}

${ }^{*} p<.001$ 
The sampled data from Table 2 show the difference between clusters 1 and 2 according to hardiness, novelty and general level of tolerance.

Table 2: Between cluster differences in hardiness and tolerance ambiguity

\begin{tabular}{|l|l|l|l|}
\hline \multicolumn{1}{|c|}{ Variables } & $\begin{array}{l}\text { Mean } \\
\text { Cluster 1 } \\
(N=59)\end{array}$ & $\begin{array}{l}\text { Mean } \\
\text { Cluster 2 } \\
(N=112)\end{array}$ & t-value \\
\hline Commitment & 43,610 & 34,357 & $\mathbf{1 2 , 1 0 8}^{*}$ \\
\hline Control & 37,305 & 28,393 & $\mathbf{1 2 , 0 6 9}^{*}$ \\
\hline Challenge & 20,237 & 16,446 & $\mathbf{5 , 1 2 4}$ \\
\hline Hardiness & 101,153 & 79,170 & 21,341 \\
\hline The novelty of the problem & 17,254 & 16,830 & 0,625 \\
\hline The complexity of the problem & 40,220 & 37,402 & $\mathbf{2 , 6 7 2}$ \\
\hline The undecidability of the problem & 9,136 & 10,777 & $\mathbf{- 2 , 9 0 0} *$ \\
\hline General score of tolerance ambiguity & 66,627 & 65,152 & 0,994 \\
\hline
\end{tabular}

Table 3 shows the difference between clusters 2 and 3 according to complexity of a problem and inability to solve it.

Table 3: Between cluster differences in hardiness and tolerance ambiguity

\begin{tabular}{|l|l|l|l|}
\hline \multicolumn{1}{|c|}{ Variables } & $\begin{array}{l}\text { Mean } \\
\text { Cluster 2 } \\
(N=112)\end{array}$ & $\begin{array}{l}\text { Mean } \\
\text { Cluster 3 } \\
(N=52)\end{array}$ & t-value \\
\hline Commitment & 34,357 & 24,173 & $\mathbf{1 2 , 5 4 5}^{*}$ \\
\hline Control & 28,393 & 21,096 & $\mathbf{9 , 1 3 4}$ \\
\hline Challenge & 16,446 & 11,692 & $\mathbf{6 , 3 0 3}$ \\
\hline Hardiness & 79,170 & 57,000 & $\mathbf{1 8 , 3 7 6}^{*}$ \\
\hline The novelty of the problem & 16,830 & 14,788 & $\mathbf{2 , 7 4 4}$ \\
\hline The complexity of the problem & 37,402 & 36,731 & 0,611 \\
\hline The undecidability of the problem & 10,777 & 10,308 & 0,847 \\
\hline General score of tolerance ambiguity & 65,152 & 61,827 & $\mathbf{2 , 1 6 4}$ \\
\hline${ }^{*} p<.001$ & \multicolumn{3}{l}{} \\
\hline
\end{tabular}

The hypothesis of the research second stage was the statement that if an individual shows a higher level of predictive competence, then their risk propensity rate is lower. Thus, their stress resistance is more effective.

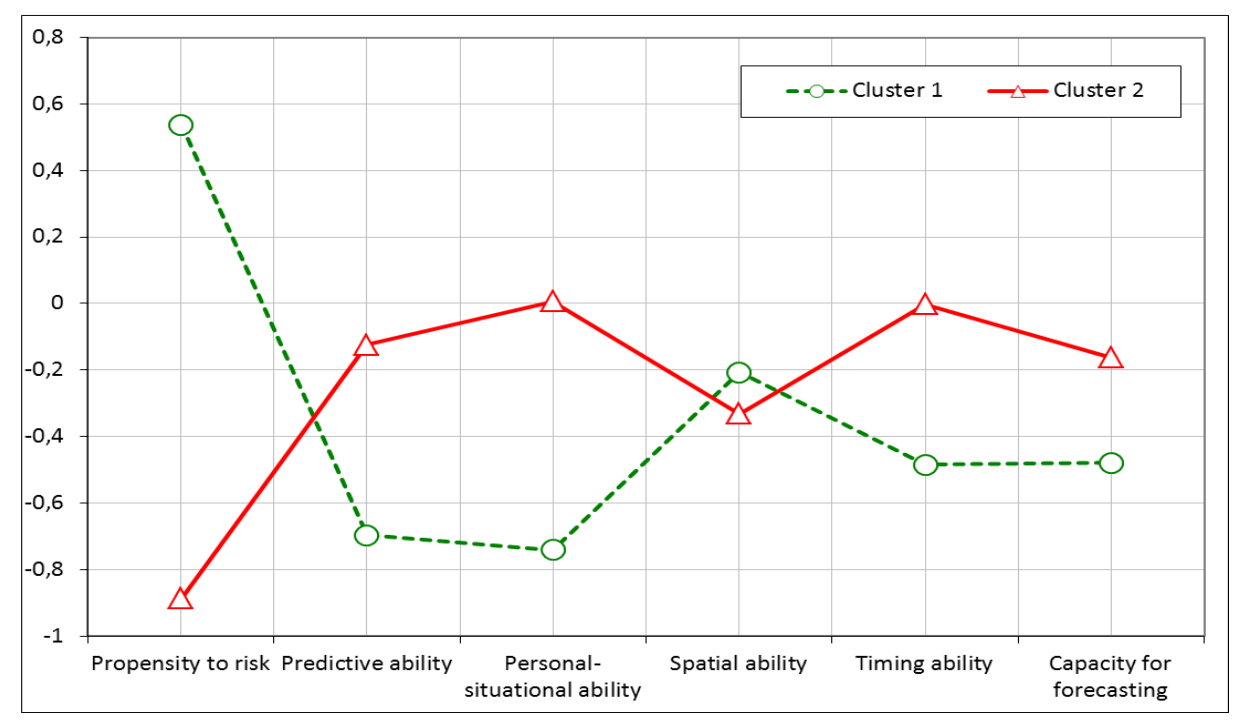

Figure 3: The results of clusterization of the sample

The first cluster with high rate of variables (analogs of independent variables) shows the highest risk propensity rate as an alternative way of coping with stress (Table 4). 
Table 4: Between cluster differences in risky behavior and prognostic variables

\begin{tabular}{|l|l|l|l|}
\hline \multicolumn{1}{|c|}{ Variables } & $\begin{array}{l}\text { Mean } \\
\text { Cluster 1 } \\
(N=65)\end{array}$ & $\begin{array}{l}\text { Mean } \\
\text { Cluster 2 } \\
(N=74)\end{array}$ & t-value \\
\hline Propensity to risk & 22,75 & 15,31 & $\mathbf{1 0 , 8 9 *}^{*}$ \\
\hline Predictive ability & 240,6 & 252,7 & $\mathbf{- 4 , 1 5 *}$ \\
\hline Personal-situational ability & 154,91 & 164,89 & $\mathbf{- 5 , 2 4}^{*}$ \\
\hline Spatial ability & 48,54 & 47,58 & 0,79 \\
\hline Timing ability & 37,06 & 40,36 & $\mathbf{- 3 , 0 2}^{* *}$ \\
\hline Capacity for forecasting & 8,89 & 9,51 & $\mathbf{- 1 , 9 5}^{* *}$ \\
\hline
\end{tabular}

${ }^{*} p<.001 ;{ }^{* *} p<.01$

As it is seen in Table 4, the opposite clusters differ greatly according to all the indices of predictive competence (person-situational, time prognostication) and ability to predict. However, such essential differences are avoided in spatial competence. According to our hypothesis, the first cluster sample shows a low level of coping behavior, prognostic abilities and future prediction and is a kind of a system unable to adapt to stress successfully.

\section{CONCLUSION}

The major findings of this research can be summed up as follows:

- High levels of the predictive competence, as the indicators of the generalized appraisal of the life situation and activity, is positive predictors of diverse repertoire of the constructive proactive coping behavior.

- High level of hardiness and low level of ambiguity intolerance guarantee an individual's successful overcoming a real-life stressful situation as we believe these personality traits demonstrate the realization of predictive characteristics of a person.

- Finally, high level of risk propensity is seen to be one of the possible variants in overcoming a real-life stressful situation.

- The role of predictive competence in psychological structure of personality is that of a stabilizer to some stressful events.

- Adaptive function of predictive competence is realized through an individual's choice of the best alternative of behavior under certain circumstances. Thus, it can be seen as a proactive coping-behavior of personality. At the same time if an individual fails to cope with the situation, to be adapted to it, they find more available routes to an appropriate behavior including its risky forms.

- Predictive competence is considered to be both an indicator of a constructive recovery from stress and an element of human mental health and well-being. Thus, in conclusion, research results suggest that predictive competence is fundamental in understanding coping ability and make a contribution to the body of research on the relationship between personality and uncertainty.

\section{References}

Aleksandrova, L.A. (2005). About constituents of the viability of personality as the basis of its psychological security in the modern world. Proceedings of Taganrog State University, Vol.51 (7), 83-84.

Amineva, Y. (2013). Meaningful characteristics of a difficult situation. Modern basic and applied research, Vol. 1 (8), 45-49.

Ananiev, BG (2000). Man as an object of knowledge. Moscow: Science.

Arshava, I. \& Bunas, A. (2013). The specificity of the predictive competence as the individual properties in the context of risky behavior. Scientific Paper of the Institute of Psychology named G. Kostiuk, 10, 4-23. 
Arshava, I. \& Nosenko, E. (2010). Self-regulated activity as a personality factor protecting from psychosomatic disorders. Proceeding of the PSYCHOLOGY \& HEALTH, 25, 290-291.

Arshava, I. \& Nosenko, E. (2013). The personality hyper-compensatory resource and its manifestation in the individual's non-verbal behavior. Proceeding of the PSYCHOLOGY \& HEALTH, 28, 281-281.

Arshava, I.F. (2008). A reflected behavioral manifestation of the human emotional stability. International journal of psychology, 43(3/4), 622-623.

Arshava, I.F., Nosenko, E.L. \& Ponomareva, L.F. (2010). Cross-situation Consistency of the Behavior Self-regulation as an Evidence of the Trait-like Nature of Coping Strategies. Materials of 15th European Conference on Personality, July 20-24; Brno, Czech Republic.

Asendorpf, J.B., Banse, R., \& Mucke, D. (2002). Double dissociation between implicit and explicit personality self-concept: The case of shy behavior. Journal of Personality and Social Psychology, 83, 380-393.

Bazilevich, T.F. (1988). Anticipation in the structure of different action plan. Psychological Journal, Vol. 9 (3), 121-131.

Bityutskaya, EV (2011). Modern approaches to the study of coping with difficult situations. Bulletin of Moscow University. Psychology, 1, 100-111.

Bodunov, M.V. (1988). Individual rate as a generalized formal-dynamic feature of the behavior. Psychological Journal, Vol. 9 (4), 33-43.

Brushlinskii, A.V. (1979). Thinking and forecasting (logical and psychological analysis). Moscow.

Bunas, A. (2012). Prognostic individual competence: the psychological analysis of the phenomenon. Materials of International Conference "Vectors of the psychology", April 23-24; Kharkiv, Ukraine.

Costa, P.T. \& MacCrae, R. (1992). Normal personality assessment in clinical practice: The NEO Personality Inventory. Psychological Assessment, Vol 4 (1), 5-13.

C. Stoycheva Talent, Science and Education: How Do We Cope with Uncertainty and Ambiguities? Institute of Psychology, Bulgarian Academy of Sciences Acad. G. Bonchev St., Blok 6, Floor 5, Sofia 1113, Bulgaria.

Endler, N.S., \& Parker, J.D.A. (1999). Coping inventory for stressful situations (CISS): Manual (2nd Ed.). Toronto: Multi-Health Systems.

Feigenberg, I.M. \& Zhuravlev, G.E. (1977). Probabilistic forecasting in human activities. Moscow: Science.

Frolova, A.V. (2010). The specifics of research of a phenomenon anticipation in speech activity. Bulletin of TSHPU, Vol. 2 (20), 11-17.

Greenwald, A.G., Banaji, M.R., Rudman, L.D., Farnham, S. D., Nosek, B.A. \& Mellot, D.S. (2002). A unified theory of implicit attitudes, stereotypes, self-esteem and self-concept. Psychological Review, 109, 3-25.

Ilyin, E.P. (2005). Psychophysiology of Human Conditions. St. Petersburg, Piter.

Ilyin, E.P. (2011). The Psychology of Risk. St. Petersburg, Piter.

Kuhl, J. \& Wassiljev, J. (1985). An Information-processing perspective on motivation: Intrinsic taskinvolvement, problem-solving, and the complexity of action plans. In G.D. Ydewalle (Ed). Cognition, Information Processing, and Motivation, (pp.505-522). Amsterdam: North-Holland.

Leontiev, D.A. \& Rasskazova, E.I. (2006). The resilience test. Moscow: Sense.

Lomov, B.F. \& Surkov, E.N. (1980). Anticipation in the structure of activity. Moscow.

Looshin, P.V., Rzhevskaya, Z.A., Dannikova, E.G., Koltko, N.A. \& Minenko, O.A. (2003). Learning to facilitate. - Manual. Kirovograd, Ukraine.

Maddi, S. \& Khoshaba, D.M. (1994). Hardiness and Mental Health. Journal of Personality Assessment. Vol. 
$63(2)$.

Maddi, S., Harvey, R., Khoshaba, D., Lu, J., Persico, M. \& Brow, M. (2006). The Personality Construct of Hardiness: Relationships with Repression, Innovativeness, Authoritarianism and Performance. Journal of Personality. Vol. 74 (32), 575-598.

Matthews, G. (2008). Personality and Information Processing: A Cognitive-Adaptive Theory. In G. Boyle, G. Matthews, and D. Saklofske (Eds). The SAGE Handbook of Personality Theory and Assessment. Vol. 1. Personality Theories and Models (pp. 56-79). Los Angeles.

Mendelevich, V.D. \& Nichiporenko, N.P. (2006). Phenomenon anticipation abilities as a subject of psychological research. Psychological Journal, Vol. 27 (5), 50-59.

Mendelevich, V.D. (1996). The anticipation mechanisms of the genesis of neurosis. Psychological Journal, 4, 107-115.

Michael, W. \& Derakshan, Nazanin (2011). New perspectives in attentional control theory. Personality and Individual Differences, 50 (7), 955-960.

Nichiporenko, N.P. (2007). The predictive competence in the personal properties. Questions of Psychology, 2, 123-130., 2, 123-130.

Nikiforov, G.S. (1980). The problem anticipation in psychology. URL: http://www.voppsy.ru/issues/1980/805/805169.htm

Nosenko, E. \& Shapoval, M. (2002). Tolerance to uncertainty as system-personal aspect of creative capability. Psychology and Society, 1, 97.

Owen William and Robert Sweeney. Ambiguity Tolerance, Performance, Learning, and Satisfaction: A Research Direction. URL http://isedj.org/isecon/2002/242c/ISECON.2002.0wen.txt

Peresleni, L.I. (1974). The features of probabilistic forecasting of children in health and disease. Questions of Psychology, 2, 115-122.

Petrova, E.A. (2004). People in the difficult life-situations. Materials of International Conference; Moscow, Russia.

Probability forecasting and presetting setup to movement. URL: http://booktoy.ru/375180/

Regush, L.A. (1981). Structure and age dynamics of the ability to predict. Psychological Journal, Vol. 2 (5), 106-115.

Study of the prediction in the psychology. URL: http://belkon.ru/content/view/734/35/

Sumina, N.E. (2007). Interconnection between anticipation consistency and personality properties and their effect on family relationships. Psychology, 14, 14-17.

Vodopiyanov, N.E. (2009). Psychological testing of the stress. St. Petersburg, Piter.

Zadiranova, G.V. (2011). Comparative analysis of the phenomenon of anticipation. URL: http://archive.nbuv.gov.ua/portal/Soc_Gum/Nvmdu/psykh/2011_7/27.pdf 